\title{
Neutrophil gelatinase-associated lipocalin (NGAL) as biomarker of acute kidney injury: a review of the laboratory characteristics and clinical evidences
}

\author{
Aldo Clerico ${ }^{1, *}$, Claudio Galli ${ }^{2}$, Antonio Fortunato ${ }^{3}$ \\ and Claudio Ronco ${ }^{4}$ \\ ${ }^{1}$ Fondazione G. Monasterio CNR-Regione Toscana and \\ Scuola Superiore Sant'Anna, Pisa, Italy \\ ${ }^{2}$ Abbott Diagnostics, Rome, Italy \\ ${ }^{3}$ Clinical Pathology Department, San Bortolo Hospital, \\ Vicenza, Italy \\ ${ }^{4}$ Department of Nephrology Dialysis and Transplantation, \\ San Bortolo Hospital and International Renal Research \\ Institute (IRRIV), Vicenza, Italy
}

\begin{abstract}
Acute kidney injury (AKI) is a common and serious condition, currently diagnosed by functional biomarkers, such as serum creatinine measurements. Unfortunately, creatinine increase is a delayed and unreliable indicator of AKI. The lack of early biomarkers of structural kidney injury has hampered our ability to translate promising experimental therapies to human AKI. The recent discovery, translation and validation of neutrophil gelatinase-associated lipocalin (NGAL), possibly the most promising novel AKI biomarker, is reviewed here. NGAL may be measured by several methods both in plasma and urine for the early diagnosis of AKI and for the prediction of clinical outcomes, such as dialysis requirement and mortality, in several common clinical scenarios, including in the intensive care unit, cardiac surgery and renal damage due the exposition to toxic agent and drugs, and renal transplantation. Furthermore, the predictive properties of NGAL, may play a critical role in expediting the drug development process. A systematic review of literature data indicates that further studies are necessary to establish accurate reference population values according to age, gender and ethnicity, as well as reliable and specific decisional values concerning the more common clinical settings related to AKI. Furthermore, proper randomized clinical trials on
\end{abstract}

\footnotetext{
*Corresponding author: Prof. Aldo Clerico, Scuola Superiore Sant'Anna, Dipartimento di Medicina di Laboratorio, Fondazione G. Monasterio CNR-Regione Toscana Via Giuseppe Moruzzi 156124 Pisa, Italy Phone: +39-0585-493569, Fax: +39-0585-493652,

E-mail: clerico@ifc.cnr.it

Received November 3, 2011; accepted January 19, 2012;

previously published online February 15, 2012
}

renal and systemic outcomes comparing the use of NGAL vs. standard clinical practice are still lacking and accurate costbenefit and/or cost-utility analyses for NGAL as biomarker of AKI are also needed. However, it is important to note that NGAL, in the absence of diagnostic increases in serum creatinine, is able to detect some patients affected by subclinical AKI who have an increased risk of adverse outcomes. These results also suggest that the concept and definition of AKI might need to be reassessed.

Keywords: acute kidney injury; creatinine; neutrophil gelatinase-associated lipocalin (NGAL); renal disease; renal function.

\section{Introduction}

The pathophysiological mechanisms related to the acute kidney injury (AKI), have progressively gained interest in the last years $(1,2)$. Indeed, despite the progressively increasing advances in diagnosis and treatment, renal injury represents an important risk factor for the development of serious complications as well as an independent mortality risk in hospitalized patients $(3,4)$. The lack of reliable biomarkers of the early structural kidney injuries results in an unacceptable delay in the clinical diagnosis, which strongly limits a prompt therapeutic approach $(4,5)$.

Although blood creatinine is commonly used as an index of renal function, creatininemia is primarily a marker of glomerular filtration and cannot be considered an ideal biomarker for the estimation of kidney injury, because it is insensitive and unreliable to diagnose renal tubular injury in the absence of significant reduction in the glomerular filtration rate (GFR) (1, 2, 5-7). Indeed, blood creatinine increases only after half of the kidney function is lost, which may take some days after the renal insult has occurred $(6,7)$. Delay in detection also means delay in intervention in the early periods of renal injury when appropriate management strategies can be instituted before irreversible renal damages occurs. Consequently, more reliable biomarkers than creatinine are necessary for both an accurate evaluation of renal function and an early detection of AKI $(1,2,7,8)$. An ideal biomarker for AKI should be non-invasive to measure, using urine or blood, rapid and inexpensive, amendable to clinical assay platforms and able to report results while damage is limitable. From a clinical standpoint, it should be 
associated with a known mechanism of renal injury, able to identify tubular damage or other primary locations of kidney damage, sensitive to establish an early diagnosis, with high gradient to allow risk stratification, specific to intrinsic AKI (vs. pre-renal) and able to discern AKI from chronic kidney disease, and the increase should be proportional to degree of damage. Finally, the results should predict clinical outcomes and efficacy of therapies and expedite drug development process.

Many biomarkers have been suggested for an accurate and early detection of AKI, as reported in Table 1 $(1,2,7)$. Among these biomarkers, only for cystatin C and NGAL, reliable and automated assay methods are commercially available (7). Moreover, the recent guidelines from the Acute Dialysis Quality Initiative (ADQI) (2) reported that only NGAL and cystatin $\mathrm{C}$ are most likely to be integrated into clinical practice in the near future.

The aim of this review article is to discuss the analytical characteristics of assay methods for NGAL and the clinical relevance of this biomarker in accordance with the principles of the evidence-based laboratory medicine. For this purpose, in September 2011, a computerized critical literature search limited to the English language in the National Library of Medicine (i.e., PubMed access to MEDLINE citations, http://www.ncbi.nlm.nih.gov/PubMed/), using the keywords: "NGAL", "NGAL assay", and "Kidney Injury", has been carried out. In the first part of this review article, we discuss the most important biochemical and physiological issues of NGAL and the analytical characteristics and performance of NGAL assay methods. In the second part of the review, we will consider the pathophysiological and clinical relevance of NGAL measurement according to the principles of evidence-based laboratory medicine.

Table 1 Novel biomarkers proposed for the detection of renal injury $(1,2,7)$.

\begin{tabular}{|c|c|}
\hline Biomarker & Related injury \\
\hline Cystatin C & Proximal tubule injury \\
\hline KIM-1 & Ischemia and nephrotoxins \\
\hline NGAL & Ischemia and nephrotoxins \\
\hline NHE3 & Ischemia, pre-renal, post-renal AKI \\
\hline $\begin{array}{l}\text { Cytokines (IL-6, IL-8, } \\
\text { IL-18) }\end{array}$ & Toxic, delayed graft function \\
\hline $\begin{array}{l}\text { N-acetyl-b-(D) } \\
\text { glucosaminidase }\end{array}$ & Tubule injury \\
\hline $\begin{array}{l}\text { Actin-actin } \\
\text { depolymerising factor }\end{array}$ & Ischemia and delayed graft function \\
\hline$\alpha-G S T$ & Proximal tubule injury, acute rejection \\
\hline$\pi-\mathrm{GST}$ & Distal tubule injury, acute rejection \\
\hline L-FABP & Ischemia and nephrotoxins \\
\hline Netrin-1 & Ischemia and nephrotoxins, sepsis \\
\hline $\begin{array}{l}\text { Keratin-derived } \\
\text { chemokine }\end{array}$ & Ischemia and delayed graft function \\
\hline
\end{tabular}

GST, glutathione S-transferase; IL, interleukin; KIM, kidney injury molecule; L-FABP, L-type fatty acid binding protein; NGAL, neutrophil gelatinase-associated lipocalin; NHE, sodium-hydrogen exchanger.

\section{NGAL: main biochemical and physiological characteristics}

NGAL (also known as human neutrophil lipocalin, lipocalin-2, siderocalin, 24p3, or LCN2) is a small molecule of 178 amino acids that belongs to the superfamily of lipocalins, which are proteins specialized in binding and transporting small hydrophobic molecules (8-11). The lipocalins share a molecular organization comprising eight $\beta$-strands arranged in a complex $\beta$-barrel structure delineating a calyx shape, which represents their binding site $(9,10)$. NGAL, like the other lipocalins, is able to bind some ligands, including the siderophores. Interactions with iron-binding siderophores give NGAL its characteristic bright red color and modulates most of its biological effects (8-11).

The biological activity of NGAL is mediated by means of bonds with specific surface receptors, including the $24 \mathrm{p} 3 \mathrm{R}$, a brain-type organic cation transporter, and the megalin multiscavenger complex, found mainly on the brush-border surface of renal tubular cells $(12,13)$. After interaction with these receptors, NGAL is internalized inside the cell as a protein alone (Apo-NGAL) or a complex with iron-binding siderophores (Holo-NGAL) (Figure 1). Holo-NGAL is captured inside endosomal vesicles and transported within the cytoplasma, where it can release the siderophore-iron complex, thus activating iron-dependent specific pathways. Conversely, Apo-NGAL, after being internalized in the cell, is able to capture cellular iron and export it to the extracellular space (Figure 1). This results in depletion of iron cellular pools that, under particular conditions, may even lead to apoptosis. Due to its specific binding to bacterial siderophores, NGAL is also able to exert a bacteriostatic effect on several strains of bacteria by its ability to capture siderophores in extracellular space and so to deplete the bacterial iron supply $(10,14,15)$. Therefore, NGAL represents a critical component of innate immunity to bacterial infection (15).

NGAL seems to have more complex activities than just its antimicrobial effect. Indeed, NGAL shows complex interactions with several other receptors and ligands, such as hepatocyte growth factor and some gelatinases (like as matrix metalloproteinase-9, MMP-9) and extracellular protein kinases (8-11), which are involved in several biological responses, such as cell proliferation and differentiation (14). The expression of NGAL rises 1000-fold in humans and rodents in response to renal tubular injury, and it appears so rapidly in the urine and serum that it is useful as an early biomarker of renal failure (14) (Figure 2). Induction of NGAL may limit tubular injury by modulating various cellular responses, such as proliferation, apoptosis, and differentiation, but the specific mechanisms for such an action are not well understood yet (14).

Human NGAL was identified and isolated from secondary granules of human neutrophils (17). NGAL mRNA is normally expressed in a variety of adult human tissues (including bone marrow, uterus, prostate, salivary gland, stomach, colon, trachea, lung, liver and kidney), which may constitutively express the NGAL protein at low levels (18). In neutrophils and urine human NGAL occurs as a monomer, with a small 


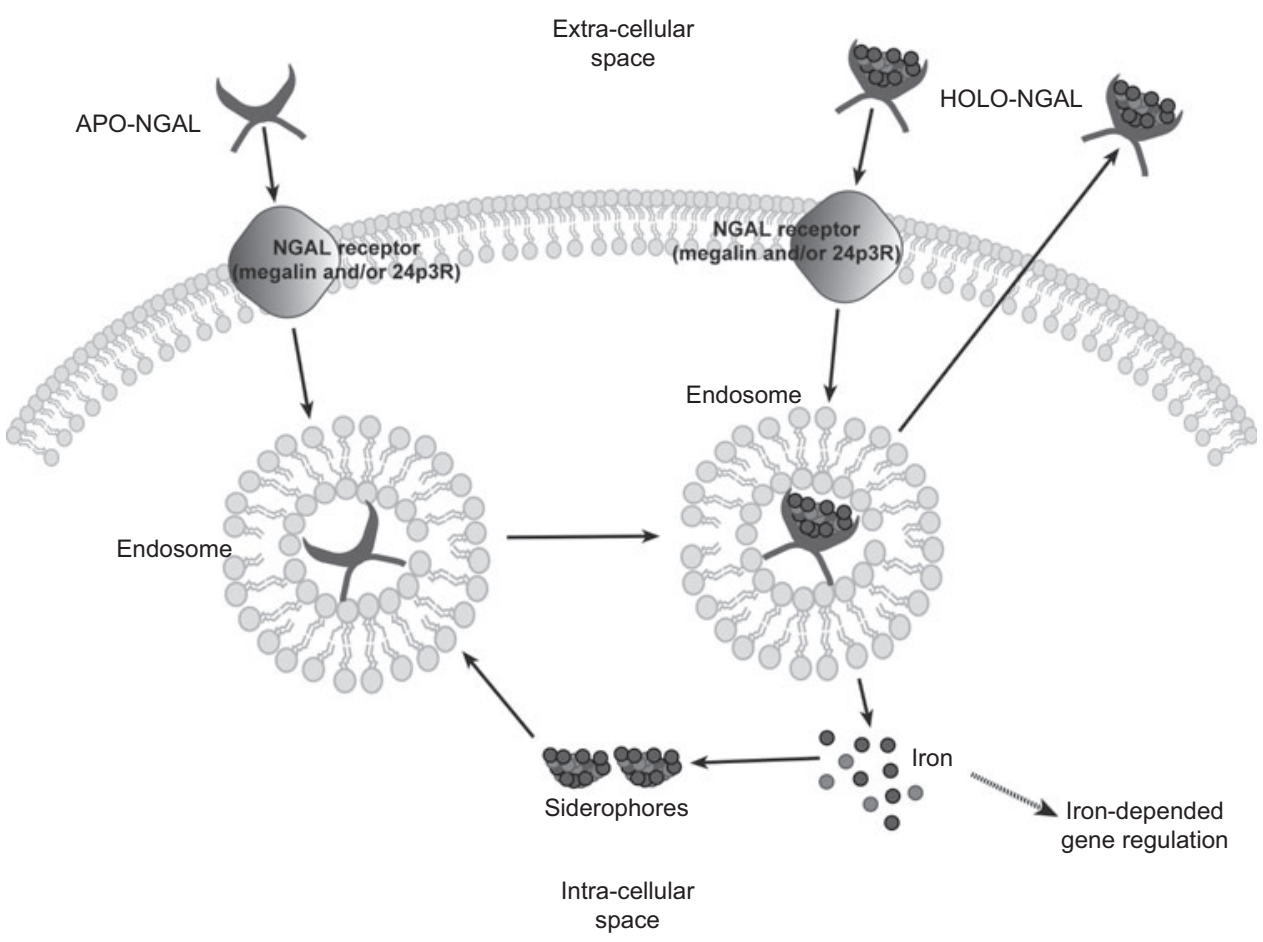

Figure 1 Schematic representation of action mechanisms of NGAL.

NGAL interacts on the cell membrane with specific receptors (24p3R and megalin) as a complex with iron-siderophores (Holo-NGAL) or alone (Apo-NGAL) (10-12). After internalization, Holo-NGAL is able to release the iron it carried into the cytoplasm, leading to iron accumulation and regulating specific iron-dependent gene pathways (10-15). Endosomal NGAL captures iron via a hypothetical intracellular siderophore, which is followed by recycling to the extracellular space (14). NGAL then may be destroyed within the cell or recycled outside as Apo-NGAL. Most protective effects attributed to this protein probably are realized through mechanisms based on iron-dependent gene regulation (10, 14, 15). Moreover, Apo-NGAL can capture intracellular iron-siderophores and transport these to the extracellular space, thus depriving the cell of its iron reserves. This probably represents the way NGAL exerts strong antibacterial properties and under particular conditions may promote cellular apoptosis $(10,14,15)$.

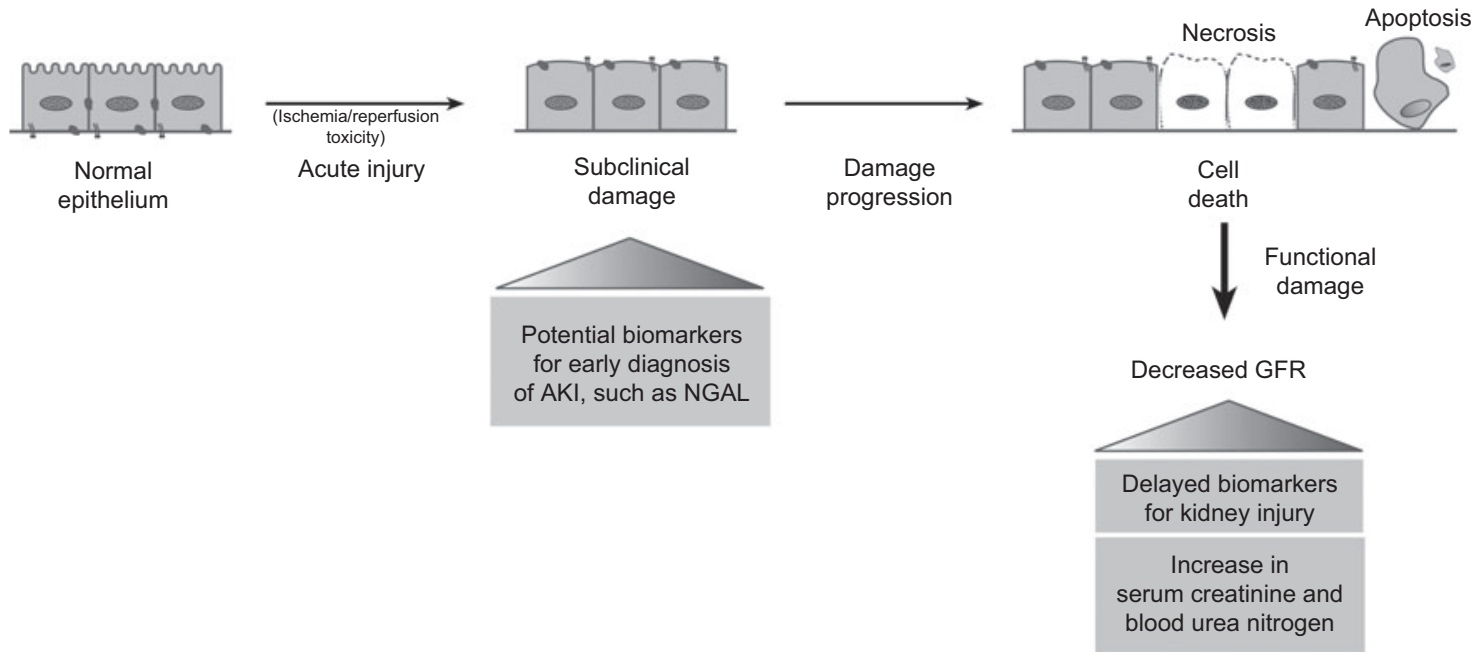

Figure 2 Clinical usefulness of biomarkers of early acute kidney injury.

The urinary and/or circulating levels of biomarkers of early acute kidney injury, such as NGAL, are increased in the urine or serum of patients within $6 \mathrm{~h}$ after the kidney injury; while blood creatinine increases only after half of the kidney function is lost, which may take some days after the renal insult has occurred $(6,7)$. Moreover, recent data suggest that NGAL assay is also able to detect patients with only subclinical or modest renal damage, which may be not revealed by significant variations in renal function test, such as serum creatinine or GFR (16). 
percentage of dimers and trimers, and it also occurs as a complex with 92-kDa human neutrophil type IV collagenase, also called gelatinase B or MMP-9. The binding of some activated transcription factors (such as the nuclear factor NF-kB) to the promoter region of the NGAL gene could explain the inducible expression of NGAL in several of the non-hematopoietic tissues (18). Moreover, the NGAL gene may be induced by a number of tumor-promoting agents, including SV40 and polyoma virus, phorbol esters, the transforming factor Neu, hepatocyte growth factor, retinoic acid, glucocorticoids and NFkB transcription factor (8). These effects may explain because NGAL is markedly induced in a number of human cancers, where it often represents a predictor of poor prognosis (8).

\section{Assay methods for NGAL measurement: analytical characteristics and performance}

Only few studies, which accurately evaluated and/or compared the analytical characteristics and performance of NGAL assay methods, are currently available in the literature (Table 2). Furthermore, the majority of the clinical studies report insufficient data on the analytical performance of the method used for NGAL assay. This lack of information does not allow an accurate evaluation and/or comparison of the analytical efficacy and reliability of NGAL measurement, especially when the methods used are manual, not standardized assays [such as enzyme-linked immunosorbent assay (ELISA) or immune blotting systems] expressly set up in the laboratory for the purpose of the study (Table 2).

The first analytical procedures set up for measurement of NGAL in blood or urine samples were based on ELISA (19, 23) or immunoblotting systems (27) (Table 2). In general, these are manual, not standardized methods, which are not recommended for clinical routine, but only for research studies (19, $20,22,23,25,27,28)$. The measurement of NGAL in serum, plasma and urine samples can be also performed by means of a commercially available ELISA kit (NGAL Rapid ELISA KIT 037, Antibodyshop ELISA kit, BioPorto Diagnostics) using both a manual procedure $(20,25)$ or several chemistry analyzers (28). Pedersen et al. (25) have recently evaluated the analytical performance of this ELISA kit, using the manual procedure for the measurement of NGAL in both urine and plasma samples. A point-of-care test (POCT) method (Triage ${ }^{\circledR}$ Bioste, Alere Health) is a commercial fluorescencebased immunoassay for a rapid measurement (approximately $30 \mathrm{~min}$ ) of NGAL in EDTA anti-coagulated whole blood or plasma samples $(21,29,30)$. This POCT method has a detection limit at $60 \mathrm{ng} / \mathrm{mL}$ and the upper limit of the working range at $1300 \mathrm{ng} / \mathrm{mL}(21,30)$.

More recently, a CMIA (chemiluminscent microparticle immunoassay) method became commercially available, using the automated platform ARCHITECT (Abbott Diagnostics) for the measurement of NGAL in urine samples $(26,29,30)$. The assay involves a microparticle reagent prepared by covalently attaching an anti-NGAL antibody to paramagnetic particles and a conjugate reagent prepared by labeling a second

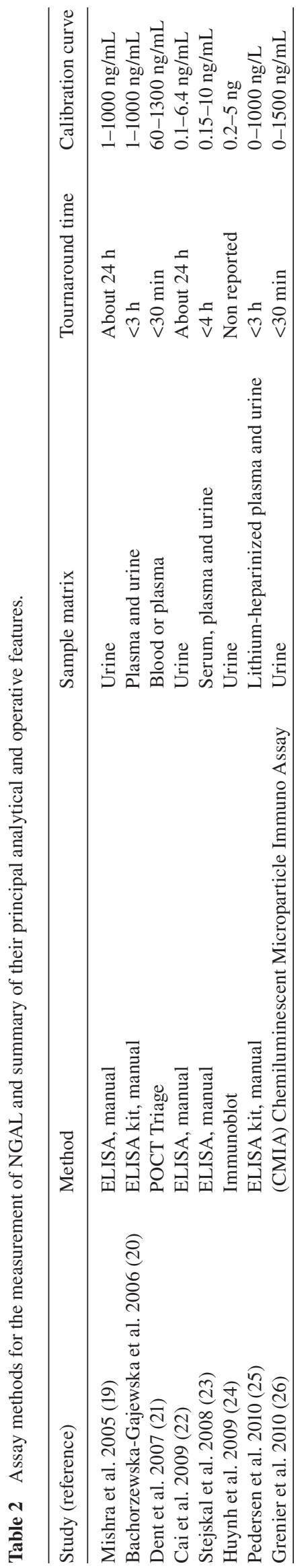


anti-NGAL antibody with acridinium. The assay calibrators are prepared with recombinant human NGAL, at concentrations $0,10,100,500,1000$ and $1500 \mathrm{ng} / \mathrm{mL}$, respectively. The analytical characteristics of this CMIA method have been recently evaluated by Grenier et al. (26). In particular, this method showed a close linear regression with an ELISA kit (AntibodyShop NGAL Rapid ELISA Kit, BioPorto, Denmark) throughout all NGAL concentration interval tested, ranging from 2 to $1500 \mu \mathrm{g} / \mathrm{L}$ ( $\mathrm{R}=0.994, \mathrm{n}=100$; ARCHITECT $=0.93$ ELISA+4.2) (26). Moreover, the imprecision at the lower limit of working range (i.e., $2 \mu \mathrm{g} / \mathrm{L}$ ) was $<20 \%$ (26).

Cavalier et al. (29) recently compared the analytical characteristics and performance of POCT Triage ${ }^{\circledR}$ method with those of CMIA method on the ARCHITECT platform. The coefficient of variation (CV) values did not exceed 6\% for the CMIA method throughout the range tested (from 22.5 to 1315 $\mu \mathrm{g} / \mathrm{L}$ ), while for the POCT Triage ${ }^{\oplus}$, the $\mathrm{CV}$ ranged from $4.9 \%$ to $15.6 \%$ at concentrations of 722 and $117 \mu \mathrm{g} / \mathrm{L}$, respectively (29). However, it is important to note that these two methods use different matrix samples: urine for CMIA and plasma for POCT Triage ${ }^{\circledast}$, respectively. Therefore, these results should be considered with care while a higher degree of precision is expected using a fully automated platform. In conclusion, a true comparison between the two testing methods is difficult to perform, also because a new version of the Triage ${ }^{\circledR}$ POCT assay, with enhanced sensitivity, will become available very soon (31).

\section{Biological variation of NGAL measurement}

Delanaye et al. (32) recently evaluated the biological variation of NGAL and the ratio between NGAL and creatinine values measured with the CMIA method in urine samples of 20 healthy subjects. Each subject collected the first-catch morning urine on ten different open days. Next, a second urine sample was randomly collected on the same day at any time. The biological variation of the first morning urine, expressed as $\mathrm{CV}$ of both absolute NGAL and NGAL/creatinine ratio values, were calculated at $84 \%$ and $81 \%$, respectively $(\mathrm{p}<0.05)$, while for the second urine random samples, the CVs were $124 \%$ and $88 \%$, respectively $(\mathrm{p}<0.05)$. Delanaye et al. $(32)$ recommend the use of NGAL to creatinine ratio values (especially for random urine samples) in order to improve the intra-individual variation observed in urinary NGAL measurements.

To provide a better assessment of the variability of urine NGAL, Grenier et al. (26) collected spot urine samples from 13 healthy volunteers, $2-4$ times per day for 3-5 days. Also in this study, the absolute urinary NGAL values and the ratio between urinary NGAL and creatinine with the CMIA method were measured. The results of this study showed that the predominant part of the variation occurred between specimens and not between days or individuals, while the contribution of the test method precision to the variance was small $(<0.5 \%)$.

From a clinical point of view, it is important to note that the biological variation of measurement of NGAL in urine specimens remains very high even after the correction for creatinine values. Obviously, this large intra-individual variation of urinary NGAL may affect its diagnostic accuracy as a biomarker of AKI. As a result, Delanaye et al. (32) suggested that NGAL samples must be doubled in longitudinal follow-up before asserting that NGAL is really increasing. However, an important limitation of these studies $(26,32)$ are that the variations of urinary NGAL values were measured only in healthy subjects, while the "true" variation of urinary NGAL in patients with AKI is not known. To the best our knowledge, there are no data regarding the biological variation of NGAL in serum or plasma specimens, and this has a definite impact on the clinical value of results.

\section{NGAL measurement: reference values}

Unfortunately, at the present time there are no available international recommendations or guidelines concerning the quality specifications for NGAL assay. For these reasons, we reported in this review, both in the text and the tables, the serum or urinary NGAL values, expressed in the same measurement units (usually $\mathrm{ng} / \mathrm{mL}$ or $\mu \mathrm{g} / \mathrm{L}$ ) of the original articles. Of course, an international standardization for the measurement units for NGAL assay is mandatory. We would like to suggest the $\mu \mathrm{g} / \mathrm{L}$ for the measurement of NGAL assay.

There are no studies intentionally set up with the aim to accurately evaluate the reference values of NGAL measurement in blood or urine specimens using large reference populations, stratified according to age, gender and ethnicity. However, some authors reported "normal values" measured in relatively large groups, including apparently healthy subjects, enrolled in a clinical study as a control group. As an example, Stejskal et al. (23) measured NGAL with an ELISA method (Table 3 ) in serum samples of adult, non-obese subjects. The NGAL values observed in the 53 men (mean: $86.3 \mu \mathrm{g} / \mathrm{L}$; SD: $43.0 \mu \mathrm{g} / \mathrm{L}$; median: $78.8 \mu \mathrm{g} / \mathrm{L}$ ) were not significantly different from those found in the 83 women (mean: $88.9 \mu \mathrm{g} / \mathrm{L}$; SD: 38.2.0 $\mu \mathrm{g} / \mathrm{L}$; median: $80.0 \mu \mathrm{g} / \mathrm{L}$ ).

Furthermore, some information on the "expected normal values" is usually reported in the product inserts of the commercial NGAL assays, distributed by the manufacturers. The expected range of NGAL normal values of Triage NGAL Test, as reported by the manufacturer, was determined by collecting blood EDTA samples from 120 apparently healthy individuals (24 females and 96 males, age range 18-83 years) (30). The non-parametric reference range upper limit (95th percentile) of the population tested was $149 \mathrm{ng} / \mathrm{mL}$ with a $90 \%$ confidence interval ranging from 100 to $194 \mathrm{ng} / \mathrm{mL}$ (30). The kit insert of the CMIA assay, distributed by Abbott Diagnostics (45), reports a value of $132 \mu \mathrm{g} / \mathrm{L}$ as the 95 th percentile of NGAL values measured in 196 blood donors. The distribution of NGAL values is highly asymmetric and approximates a log-normal distribution.

To our knowledge, there is no reliable literature data concerning the reference range of NGAL measured in urine or blood samples in pediatric age. Huynh et al. (24) recently reported NGAL values measured by an immunoblotting procedure (Table 2) in 706 samples collected from 50 neonates 


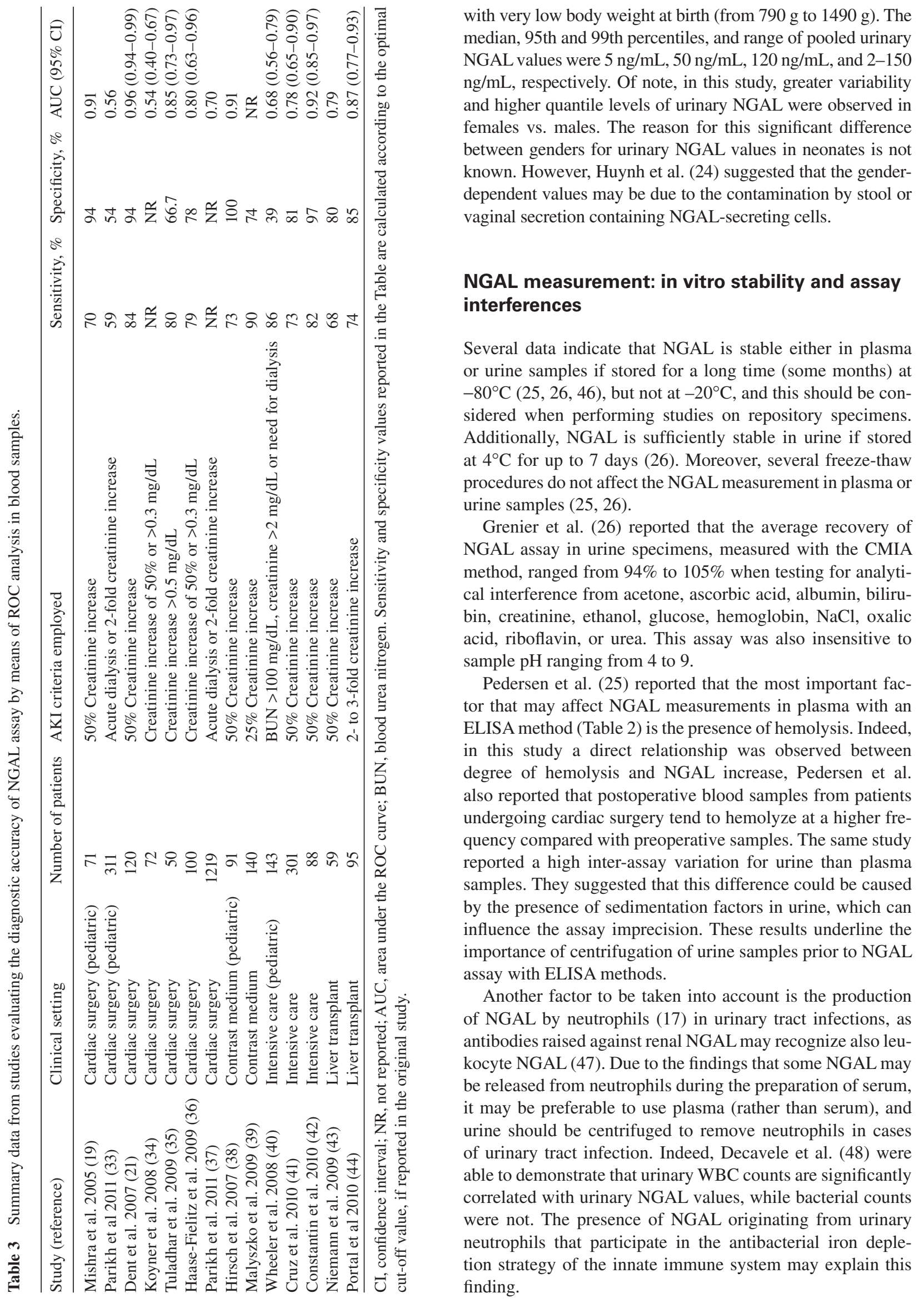

with very low body weight at birth (from $790 \mathrm{~g}$ to $1490 \mathrm{~g}$ ). The median, 95th and 99th percentiles, and range of pooled urinary NGAL values were $5 \mathrm{ng} / \mathrm{mL}, 50 \mathrm{ng} / \mathrm{mL}, 120 \mathrm{ng} / \mathrm{mL}$, and 2-150 $\mathrm{ng} / \mathrm{mL}$, respectively. Of note, in this study, greater variability served in between genders for urinary NGAL values in neonates is not known. However, Huynh et al. (24) suggested that the genderdependent values may be due to the contamination by stool or vaginal secretion containing NGAL-secreting cells.

\section{NGAL measurement: in vitro stability and assay}

Several data indicate that NGAL is stable either in plasma or urine samples if stored for a long time (some months) at be conAdditionally, NGAL is sufficiently stable in urine if stored at $4^{\circ} \mathrm{C}$ for up to 7 days (26). Moreover, several freeze-thaw procedures do not affect the NGAL measurement in plasma or rine samples $(25,26)$.

Grenier et al. (26) reported that the average recovery of NGAL assay in urine specimens, measured with the CMIA cal interferenc bin, creatinine, ethanol, glucose, hemoglobin, $\mathrm{NaCl}$, oxalic acid, riboflavin, or urea. This assay was also insensitive to ample $\mathrm{pH}$ ranging from 4 to 9 .

Pedersen et al. (25) reported that the most important factor that may affect NGAL measurements in plasma with an ELISA method (Table 2) is the presence or hemolysis. Indeed, degree of hemolysis and NGAL increase, Pedersen et al. also reported that postoperative blood samples from patients undergoing cardiac surgery tend to hemolyze at a higher frequency compared with preoperative samples. The same study reported a high inter-assay variation for urine than plasma samples. They suggested that this difference could be caused by the presence of sedimentation factors in unine, which can importance of centrifugation of urine samples prior to NGAL assay with ELISA methods.

Another factor to be taken into account is the production of NGAL by neutrophils (17) in urinary tract infections, as antibodies raised against renal NGAL may recognize also leukocyte NGAL (47). Due to the findings that some NGAL may it may be preferable to use plasma (rather than serum), and urine should be centrifuged to remove neutrophils in cases of urinary tract infection. Indeed, Decavele et al. (48) were able to demonstrate that urinary WBC counts are significantly correlated with urinary NGAL values, while bacterial counts were not. The presence of NGAL originating from urinary tion stralegy of the inte immune systen may explan this finding. 


\section{NGAL measurement: pathophysiological considerations}

From a clinical point of view, the use of NGAL assay is currently suggested for the diagnostic and/or prognostic evaluation of AKI syndromes, also including patients with cardio-renal syndrome related to heart failure $(1,2,16,33-44$, 49-68). The rationale for these clinical applications of NGAL assay is strictly associated to pathophysiological mechanisms responsible of AKI (Figure 2).

AKI refers to a common syndrome that results from multiple causative factors and occurs in a variety of clinical settings, with clinical manifestations of different degrees of severity, ranging from a minimal elevation in serum creatinine to anuric renal failure $(1,2,8)$. AKI is a common clinical situation in hospitalized patients, in particular in critical care and surgical perioperative settings. These patients often suffer a worse clinical outcome, including prolonged hospitalization, the need for admission to the intensive care unit, the need for dialysis, development of chronic kidney disease, and an increased mortality. The incidence of AKI in hospitalized patients is estimated at a staggering $5 \%-7 \%$, while in the intensive care units it is even higher (approx. 25\%) (8). Despite recent improvement in outcomes over time, reported incidence and mortality rates are still high though they vary widely in the literature, with incidence ranging from $1 \%$ to $31 \%$ and mortality from $28 \%$ to $82 \%(1,2,8)$.

The term AKI has largely replaced that of acute renal failure; as the latter designation overemphasizes the failure of kidney function and fails to account for the diverse molecular, biochemical and structural processes that characterize the AKI syndrome (8). Indeed, the pathogenesis of AKI involves the complex interaction between vascular, tubular, and inflammatory factors $(69,70)$. The kidney is believed to be highly susceptible to injury related to ischemia and/or toxins resulting in vasoconstriction, endothelial injury, and activation of innate and acquired inflammatory immune responses $(69,70)$. This susceptibility derives, in part, from the association between vascular supply to the outer medulla, where tubular cells are vulnerable to ischemia/hypoxia, and the natural functional response of the nephron to filter, concentrate, and potentially reabsorb many substances from the tubular lumen that may predispose to local epithelial cell toxicity $(69,70)$. The most common nephrotoxic agents have been described by Bagshaw et al. (69).

Injured kidney tubular cells produce and secrete several biological substance associated to innate and acquired inflammatory immune responses, including $\operatorname{NGAL}(69,70)$. In the kidney, after ischemic or nephrotoxic AKI in animal models, transcriptome profiling studies identified NGAL to be one of the most up-regulated gene, and proteomic analyses revealed NGAL to be one of the most highly induced proteins (71-74). These studies stimulated several groups of investigators to evaluate NGAL as a non-invasive biomarker in human AKI (8). As a result, a huge number of studies have now implicated NGAL as an early diagnostic biomarker for AKI in common clinical situations (16, 33-44, 49-68).

The genesis and sources of plasma and urinary NGAL following an acute kidney injury require further clarification.
Although plasma NGAL is freely filtered by the glomerulus, it is largely reabsorbed in the proximal tubules by efficient megalin-dependent endocytosis (75). Thus, any urinary excretion of NGAL should occur only when there is a concomitant proximal renal tubular injury that precludes NGAL reabsorption and/or increases de novo NGAL synthesis. With respect to plasma NGAL, the kidney itself does not appear to be a major source (75). In animal studies, direct ipsilateral renal vein sampling after unilateral ischemia indicates that the NGAL synthesized in the kidney is not introduced efficiently into the circulation, but is abundantly present in the ipsilateral ureter (14). However, recent findings indicate that NGAL mRNA expression is increased in distant organs after acute kidney injury (76), especially the liver and lungs. As a result over-expressed NGAL protein released into the circulation may constitute a distinct systemic pool (75). Indeed, NGAL is an acute phase reactant and may be released from neutrophils, macrophages and other immune cells into circulation following kidney damage. Furthermore, any decrease in GFR resulting from AKI would be expected to decrease the renal clearance of NGAL, with subsequent accumulation in the systemic circulation. However, the relative contribution of these mechanisms to the rise in plasma NGAL after AKI remains to be determined.

\section{Clinical relevance of NGAL measurement according to the principles of evidence-based laboratory medicine}

In Tables 3 and 4, we have summarized the data from several studies that evaluated the diagnostic accuracy of NGAL testing in blood (Table 3) and urine (Table 4) samples in different clinical conditions associated to AKI syndromes. Only the studies that assessed the diagnostic accuracy according to evidence-based laboratory medicine principles were taken into consideration. A large variation of diagnostic accuracy was reported in these studies, with area under the curve (AUC) values ranging from 0.54 to 0.96 for NGAL in blood samples (Table 3 ) and from 0.61 to 0.98 for urine samples (Table 4). This shows some studies reported a good or excellent diagnostic accuracy of the NGAL assays, while other ones evidenced a very poor or not significant discrimination between patients with or without AKI. These very large differences in the results reported are probably due to both the low number of patient enrolled in some studies and to the evaluation of different clinical settings. Considering these limitations, a recent meta-analysis (49) was performed in order to evaluate more precisely the diagnostic accuracy of NGAL as a biomarker of AKI. Using a hierarchical bivariate generalized linear model to calculate the diagnostic odds ratio (DOR) and sample size-weighted area under the curve (AUC), for the receiveroperating characteristic, Hasse et al. analyzed data from 19 studies and 8 countries involving 2538 patients, of whom 487 (19.2\%) developed AKI (49). Considering all data as a whole, the DOR and AUC of NGAL measurements to predict AKI was 18.6 and 0.815 , respectively. A separate analysis according to the different clinical setting has been also carried out: 


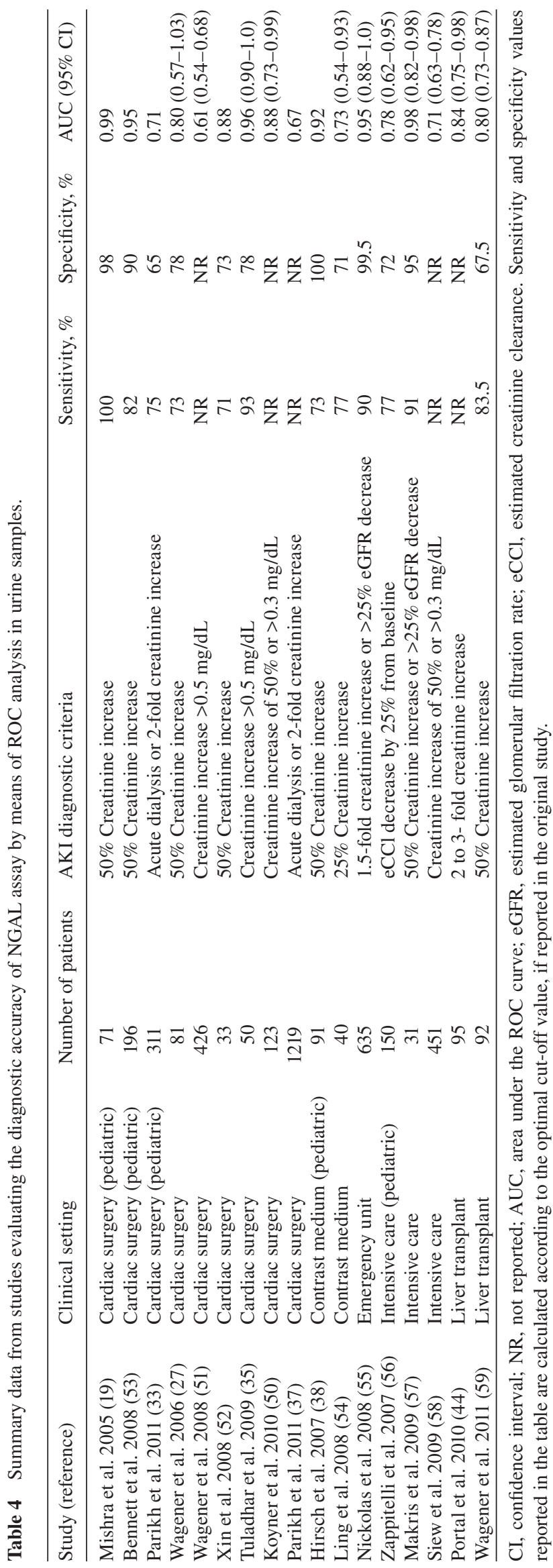

in cardiac surgery patients, the DOR and AUC of NGAL was 13.1 and 0.775 ; in critically ill patients, 10.0 and 0.728 ; and after contrast infusion, 92.0 and 0.894 . The diagnostic accuracy of plasma/serum NGAL (DOR 17.9, AUC 0.775) was similar to that of urine NGAL (DOR 18.6 and AUC 0.83). Finally, this study indicated age to be an effective modifier of NGAL value with better predictive ability in children (DOR 25.4 and AUC 0.930) compared with adults (DOR 10.6 and AUC 0.782) (49).

This meta-analysis indicated that NGAL assay may be also a useful prognostic tool with regard to the prediction of renal replacement therapy initiation (DOR 12.9 and AUC 0.782) and in-hospital mortality (DOR 8.8 and AUC 0.706) (49). The prognostic accuracy of NGAL assay was confirmed by a more recent meta-analysis (16), which analyzed pooled data from 2322 critically ill patients with predominantly cardiorenal syndrome from ten prospective observational studies of NGAL. This analysis indicates that in the absence of diagnostic increases in serum creatinine, NGAL detects patients with likely subclinical AKI, who have an increased risk of adverse outcomes.

In the last few years, a progressively increasing number of studies suggested that NGAL is a useful diagnostic and prognostic biomarker in the specific setting of cardio-renal syndrome $(1,2)$, including patients with chronic or acute heart failure (61-68). In particular, some studies $(61-64,66)$ reported that NGAL, measured in urine or plasma samples, is as sensitive early marker of renal injury, including patients with chronic heart failure with reduced eGFR, even when serum creatinine is normal (61). Moreover, recent studies indicated that NGAL is also a prognostic marker in patients with heart failure $(63,64,67,68)$. In elderly patients, higher levels of plasma NGAL are related to the clinical severity of congestive heart failure, the highest levels being reached in patients with NYHA functional class IV, and were associated with higher mortality (63). More recently, the GALLANT multicenter, prospective study (68) assessed the utility of plasma NGAL, alone and in combination with BNP, as an early risk marker of adverse outcomes in 186 patients $(61 \%$ male) in acutely decompensated heart failure. In this study, 29 events (readmissions for acute hart failure and all-cause mortality) were observed at 30 days (16\%). Patients with events had higher mean levels of NGAL than those without (134 $\mathrm{ng} / \mathrm{mL}$ vs. $84 \mathrm{ng} / \mathrm{mL})$. The area under the AUC was higher for NGAL (0.72) than BNP (0.65), serum creatinine (0.57), or eGFR (0.55). In multivariable analyses, NGAL significantly predicted events, BNP only approached significance, while neither serum creatinine nor eGFR were significant.

Although these data, taken as a whole (61-68), suggest a relevant role for NGAL as biomarker of AKI in patients of heart failure, further studies are needed to accurately evaluate the diagnostic and prognostic relevance of this biomarker in this specific clinical setting, as the majority of the above reported studies enrolled a small group of patients (61-66) and/or used an inadequate statistical analysis, according to the evidence-based laboratory medicine principles. Indeed, only the GISSI-heart failure trial (68) has enrolled an adequate number of cases (2130 patients with heart failure) for a 
reliable statistical evaluation of the prognostic accuracy and the clinical outcome. As a result, the efficiency and efficacy of the use of NGAL assay in the specific setting, including only patients with heart failure, are, at present time, not well demonstrated, while studies reporting the cost-benefit analysis are completely lacking.

Another relevant field for the clinical application of NGAL assays is the renal transplant setting (77-86). Patients undergoing renal transplantation, especially from deceased donors, often experience a delayed graft function (DGF) that is the main risk factor for reduced allograft survival, and currently DGF is diagnosed by measuring serum creatinine, thence with the same problems, especially in timing, experienced for the diagnosis of AKI. NGAL expression was shown (77) to be significantly increased in cadaveric than in living renal allografts ( $2.3 \pm 0.8$ vs. $0.8 \pm 0.7$ by an "ad hoc" scoring system) and there was a strong correlation between NGAL staining and peak postoperative serum creatinine, which occurred days later $(\mathrm{R}=0.86, \mathrm{p}<0.001)$. Parikh et al. (78). suggested a possible improvement in DGF diagnosis by measuring NGAL and IL-18 in urine, with an AUC of 0.9 for both markers. The same two markers were evaluated also by Hall et al. (83), who reached the conclusion that the levels of both markers on the first day after transplant were predictors of dialysis initiation and recovery of graft function after 3 months. Kusaka et al. (79) reported NGAL measurement in plasma as a good predictor of DGF recovery. However, subsequent studies either on plasma $(80-82,85)$ or urine $(84,86)$ NGAL yielded conflicting results, with AUCs ranging from 0.63 to 0.97 and the lowest value was obtained in the only study (86) conducted on a large number of patients $(n=598)$.

\section{NGAL measurement: state-of-art and prospective remarks}

By now, a huge number of clinical studies (Tables 3-5) and systematic reviews indicate that NGAL should be considered a reliable diagnostic and prognostic biomarker for kidney injury $(2,7,8,16,33-44,49-85)$. However, reference ranges, adjusted for age, gender and ethnicity, as well as reliable cutoff values, calculated on large patient population, for ruling in and out of AKI syndromes, are still lacking. Furthermore, proper randomized clinical trials on renal and systemic outcomes comparing the use of NGAL vs. standard clinical practice are still lacking and accurate cost-benefit and/or cost-utility analyses are needed in order to demonstrate that NGAL assay is able to improve diagnostic algorithms and/or outcome of patients, as well as to reduce the cost of clinical care.

Some authors $(8,32,75)$ have compared the possible clinical impact of NGAL assays, as a biomarker of acute renal injury, to that of cardiac troponins $\mathrm{I}(\mathrm{cTnI})$ and $\mathrm{T}(\mathrm{cTnT})$ on acute coronary syndromes. However, it is important to note that while cTnI and cTnT are biomarkers absolutely specific for cardiac tissue (87), NGAL is not a biomarker specific for renal tissue, because it is produced and secreted by several other tissues (including bone marrow, uterus, prostate,

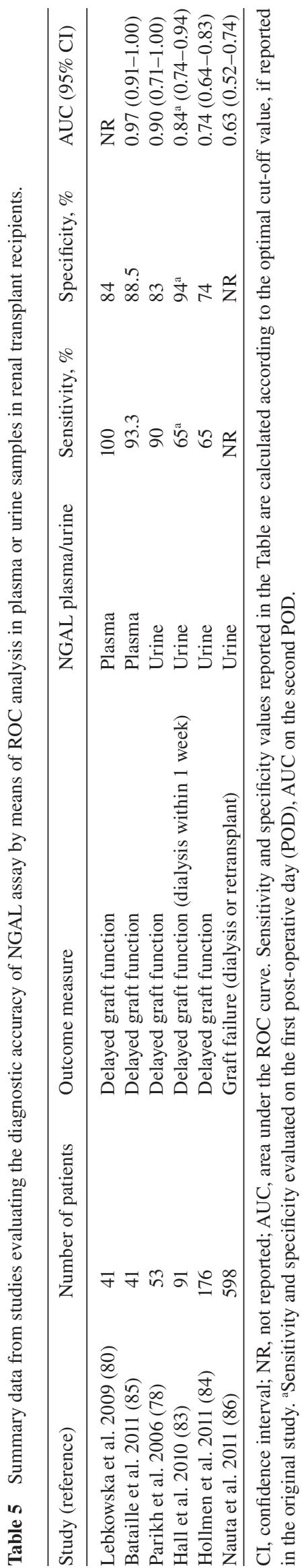


salivary gland, stomach, colon, trachea, lung, liver and kidney) (8). Therefore, while an increase in circulating levels of cTnI and cTnT always indicates a cardiac damage (87), an increase in NGAL may be due to damage or altered functional activity of other organs and tissues (such as immune competent cells) different to renal tissue. NGAL assays in urine samples may improve specificity compared to that in blood (serum or plasma), but the evidences reported so far do not confirm this hypothesis (49). However, it is important to note that NGAL assays, in the absence of diagnostic increases in serum creatinine, are able to detect some patients, affected by subclinical AKI, who have an increased risk of adverse outcomes (16). These results may indicate that the concept and definition of AKI (currently still based on the measurement of serum creatinine and urinary flow) $(1,2)$ might need reassessment (16).

\section{Conflict of interest statement}

Authors' conflict of interest disclosure: The authors stated that there are no conflicts of interest regarding the publication of this article.

Research funding: None declared.

Employment or leadership: None declared.

Honorarium: None declared.

\section{References}

1. Ronco C, Haapio M, House AA, Anavekar N, Bellomo R. Cardiorenal sindrome. J Am Coll Cardiol 2008;52:1527-39.

2. Ronco C, McCullough P, Anker SD, Anand I, Aspromonte N, Bagshaw SM, et al. Cardio-renal syndromes: report from the consensus conference of the Acute Dialysis Quality Initiative. Eur Heart J 2010;31:703-11.

3. Coca SG, Peixoto AJ, Garg AX, Krumholz HM, Parikh CR. The prognostic importance of a small acute decrement in kidney function in hospitalized patients: a systematic review and metaanalysis. Am J Kidney Dis 2007;50:712-20.

4. Coca SG, Yusuf B, Shlipak MG, Garg AX, Parikh CR. Long-term risk of mortality and other adverse outcomes after acute kidney injury: a systematic review and meta-analysis. Am J Kidney Dis 2009;53:961-73.

5. McCullough PA, Haapio M, Mankad S, Zamperetti N, Massie B, Bellomo R, et al. Prevention of cardio-renal syndromes: workgroup statements from the 7th ADQI Consensus Conference. Nephrol Dial Transplant 2010;25:1777-84.

6. Bellomo R, Kellum JA, Ronco C. Defining acute renal failure: physiological principles. Intensive Care Med 2004;30:33-7.

7. Cruz DN, Goh CY, Palazzuoli A, Slavin L, Calabrò A, Ronco C, et al. Laboratory parameters of cardiac and kidney dysfunction in cardio-renal syndromes. Heart Fail Rev 2011;16:545-51.

8. Devarajan P. Neutrophil gelatinase-associated lipocalin: a promising biomarker for human acute kidney injury. Biomarkers Med 2010;4:265-80.

9. Flower DR, North AT, Attwood TK. Structure and sequence relationships in the lipocalins and related proteins. Protein Sci 1993;2:753-61.

10. Clifton MC, Corrent C, Strong RK. Siderocalins: siderophorebinding proteins of the innate immune system. Biometals 2009;22:557-64.
11. Borregaard N, Cowland JB. Neutrophil gelatinase-associated lipocalin, a siderophore-binding eukaryotic protein. Biometals 2006;19:211-5.

12. Devireddy LR, Gazin C, Zhu X, Green MR. A cell surface receptor for lipocalin $24 \mathrm{p} 3$ selectively mediates apoptosis and iron uptake. Cell 2005;123:1293-305.

13. Hvidberg V, Jacobsen C, Strong RK, Cowland JB, Moestrup SK, Borregaard N. The endocytic receptor megalin binds the iron transporting neutrophil-gelatinase-associated lipocalin with high affinity and mediates its cellular uptake. FEBS Lett 2005;579:773-7.

14. Schmidt-Ott KM, Mori K, Li JY, Kalandadze A, Cohen DJ, Devarajan P, et al. Dual action of neutrophil gelatinase-associated lipocalin. J Am Soc Nephrol 2007;18:407-13.

15. Flo TH, Smith KD, Sato S, Rodriguez DJ, Holmes MA, Strong RK, et al. Lipocalin 2 mediates an innate immune response to bacterial infection by sequestrating iron. Nature 2004;432:917-21.

16. Haase M, Devarajan P, Haase-Fielitz A, Bellomo R, Cruz DN, Wagener G, et al. The outcome of neutrophil gelatinaseassociated lipocalin-positive subclinical acute kidney injury-a multicenter pooled analysis of prospective studies. J Am Coll Cardiol 2011;57:1752-61.

17. Xu SY, Carlson M, Engström A, Garcia R, Peterson CG, Venge P. Purification and characterization of a human neutrophil lipocalin (HNL) from the secondary granules of human neutrophils. Scand J Clin Lab Invest 1994;54:365-76.

18. Cowland JB, Borregaard N. Molecular characterization and pattern of tissue expression of the gene for neutrophil gelatinaseassociated lipocalin from humans. Genomics 1997;45:17-23.

19. Mishra J, Dent C, Tarabishi R, Mitsnefes MM, Ma Q, Kelly $\mathrm{C}$, et al. Neutrophil gelatinase-associated lipocalin (NGAL) as a biomarker for acute renal injury after cardiac surgery. Lancet 2005;365:1231-8.

20. Bachorzewska-Gajewska H, Malyszko J, Sitniewska E, Malyszko JS, Dobrzycki S. Neutrophil-gelatinase-associated lipocalin and renal function after percutaneous coronary interventions. Am J Nephrol 2006;26:287-92.

21. Dent CL, Ma Q, Dastrala S, Bennett M, Mitsnefes MM, Barasch J, et al. Plasma neutrophil gelatinase-associated lipocalin predicts acute kidney injury, morbidity and mortality after pediatric cardiac surgery: a prospective uncontrolled cohort study. Crit Care 2007;11:R127.

22. Cai L, Borowiec J, Xu S, Han W, Venge P. Assays of urine levels of HNL/NGAL in patients undergoing cardiac surgery and the impact of antibody configuration on their clinical performances. Clin Chim Acta 2009;403:121-5.

23. Stejskal D, Karpísek M, Humenanska V, Hanulova Z, Stejskal P, Kusnierova P, et al. Lipocalin-2: development, analytical characterization, and clinical testing of a new ELISA. Horm Metab Res 2008;40:381-5.

24. Huynh TK, Bateman DA, Parravicini E, Lorenz JM, Nemerofsky SL, Sise ME, et al. Reference values of urinary neutrophil gelatinase-associated lipocalin in very low birth weight infants. Pediatr Res 2009;66:528-32.

25. Pedersen KR, Ravn HB, Hjortdal VE, Nørregaard R, Povlsen JV. Neutrophil gelatinase-associated lipocalin (NGAL): validation of commercially available ELISA. Scand J Clin Lab Invest 2010;70:374-82.

26. Grenier FC, Ali S, Syed H, Workman R, Martens F, Liao M, et al. Evaluation of the ARCHITECT urine NGAL assay: Assay performance, specimen handling requirements and biological variability. Clin Biochem 2010;43:615-20.

27. Wagener G, Jan M, Kim M, Mori K, Barasch JM, Sladen RN, et al. Association between increases in urinary neutrophil 
gelatinase-associated lipocalin and acute renal dysfunction after adult cardiac surgery. Anesthesiology 2006;105:485-91.

28. NGAL Rapid ELISA kit (KIT 037). Information included in the commercial web site (http://www.ngal.com/).

29. Cavalier E, Bekaert AC, Carlisi A, Legrand D, Krzesinski JM, Delanaye P. Neutrophil gelatinase-associated lipocalin (NGAL) determined in urine with the Abbott Architect or in plasma with the Biosite Triage? The laboratory's point of view. Clin Chem Lab Med 2011;49:339-41.

30. Triage NGAL Test (REF 98400EU). Biosite, Product insert. Inverness Medical, 01/08/2009.

31. Ronco C, Cruz D, Noland B. Neutrophil gelatinase-associated lipocalin curve and neutrophil gelatinase associated lipocalin extended-range assay: a new biomarker approach in the early diagnosis of acute kidney injury and cardio-renal syndrome. Semin Nephrol 2012;32:121-8.

32. Delanaye P, Rozet E, Krzesinski JM, Cavalier E. Urinary NGAL measurement: biological variation and ratio to creatinine. Clin Chim Acta 2011:412:390.

33. Parikh CR, Devarajan P, Zappitelli M, Sint K, Thiessen-Philbrook $\mathrm{H}$, Li S, et al. Postoperative biomarkers predict acute kidney injury and poor outcomes after pediatric cardiac surgery. J Am Soc Nephrol 2011;22:1737-47.

34. Koyner J, Bennett M, Worcester E, Ma Q, Raman J, Jeevanandam $\mathrm{V}$, et al. Urinary cystatin $\mathrm{C}$ as an early biomarker of acute kidney injury following adult cardiothoracic surgery. Kidney Int 2008;74:1059-69.

35. Tuladhar SM, Puntmann VO, Soni M, Punjabi PP, Bogle RG. Rapid detection of acute kidney injury by plasma and urinary neutrophil gelatinase-associated lipocalin after cardiopulmonary bypass. J Cardiovasc Pharmacol 2009;53:261-6.

36. Haase-Fielitz A, Bellomo R, Devarajan P, Story D, Matalanis G, Dragun $\mathrm{D}$, et al. Novel and conventional serum biomarkers predicting acute kidney injury in adult cardiac surgery - a prospective cohort study. Crit Care Med 2009;37:553-60.

37. Parikh CR, Coca SG, Thiessen-Philbrook H, Schlipak MG, Koyner JL, Wang Z, et al. Postoperative biomarkers predict acute kidney injury and poor outcomes after adult cardiac surgery. J Am Soc Nephrol 2011;22:1748-57.

38. Hirsch R, Dent C, Pfriem H, Allen J, Beekman RH, Ma Q, et al. NGAL is an early predictive biomarker of contrast-induced nephropathy in children. Pediatr Nephrol 2007;22:2089-95.

39. Malyszko J, Bachorzewska-Gajewska H, Poniatowski B, Malyyszko JS, Dobrzycki S. Urinary and serum biomarkers after cardiac catheterization in diabetic patients with stable angina and without severe chronic kidney disease. Ren Fail 2009;31:910-19.

40. Wheeler DS, Devarajan P, Ma Q, Harmon K, Monaco M, Cvijanovich N, et al. Serum neutrophil gelatinase-associated lipocalin (NGAL) as a marker of acute kidney injury in critically ill children with septic shock. Crit Care Med 2008;36:1297-303.

41. Cruz DN, de Cal M, Garzotto F, Perazella MA, Leitini P, Corradi $\mathrm{V}$, et al. Plasma neutrophil gelatinase-associated lipocalin is an early biomarker for acute kidney injury in an adult ICU population. Int Care Med 2010;36:444-51.

42. Constantin J-M, Futier E, Perbet S, Roszyk L, Lautrette A, Gillard T, et al. Plasma neutrophil gelatinase-associated lipocalin is an early marker of acute kidney injury in adult critically ill patients: a prospective study. J Crit Care 2010;25:176:e1-6.

43. Niemann CU, Walia A, Waldman J, Davio M, Roberts JP, Hirose $\mathrm{R}$, et al. Acute kidney injury during liver transplantation as determined by neutrophil gelatinase-associated lipocalin. Liver Transpl 2009;15:1852-60.

44. Portal AJ, McPhail MW, Bruce M, Coltart I, Slack A, Sherwood $\mathrm{R}$, et al. Neutrophil gelatinase-associated lipocalin predicts acute kidney injury in patients undergoing liver transplantation. Liver Transpl 2010;16:1257-66.

45. Urine NGAL (REF 1P37). Product insert. Abbott Diagnostics Division, Longford, Ireland, 2009.

46. Haase-Fielitz A, Haase M, Bellomo R. Instability of urinary NGAL during long-term storage. Am J Kidney Dis 2009;53:564-5.

47. Cai L, Rubin J, Han W, Venge P, Xu S. The origin of multiple molecular forms in urine of HNL/NGAL. Clin J Am Soc Nephrol 2010;5:2229-35.

48. Decavele AC, Dhondt L, De Buyzere ML, Delanghe J. Increased urinary neutrophil gelatinase associated lipocalin in urinary tract infections and leukocyturia. Clin Chem Lab Med 2011;49:999-1003.

49. Haase M, Bellomo R, Devarajan P, Schlattmann P, Haase-Fielitz A. Accuracy of neutrophil gelatinase-associated lipocalin (NGAL) in diagnosis and prognosis in acute kidney injury: a systematic review and meta-analysis. Am J Kidney Dis 2009;54:1012-24.

50. Koyner J, Vaidya VS, Bennett MR, Ma Q, Worcester E, Akhter $\mathrm{SA}$, et al. Urinary biomarkers in the clinical prognosis and early detection of acute kidney injury Clin J Am Soc Nephrol 2010:5:2154-65.

51. Wagener G, Gubitosa G, Wang S, Borregaard N, Kim M, Lee HT. Urinary neutrophil gelatinase-associated lipocalin and acute kidney injury after cardiac surgery. Am J Kidney Dis 2008;52:425-33.

52. Xin C, Yulong X, Yu C, Changchun C, Feng Z, Xinwei M. Urine neutrophil gelatinase-associated lipocalin and interleukin-18 predict acute kidney injury after cardiac surgery. Ren Fail 2008;30:904-13.

53. Bennett M, Dent CL, Ma Q, Dastrala S, Grenier F, Workman R, et al. Urine NGAL predicts severity of acute kidney injury after cardiac surgery: A prospective study. Clin J Am Soc Nephrol 2008;3:665-73.

54. Ling W, Zhaohui N, Ben H, Leyi G, Janping L, Huili D, et al. Urinary IL-18 and NGAL as early predictive biomarkers in contrast-induced nephropathy after coronary angiography. Nephron Clin Pract 2008;108:c176-81.

55. Nickolas TL, O'Rourke MJ, Yang J, Sise ME, Canetta PA, Barasch N, et al. Sensitivity and specificity of a single emergency department measurement of urinary neutrophil gelatinase-associated lipocalin for diagnosing acute kidney injury. Ann Intern Med 2008;148:810-19.

56. Zappitelli M, Washburn KM, Arikan AA, Loftis L, Ma Q, Devarajan P, et al. Urine NGAL is an early marker of acute kidney injury in critically ill children. Crit Care 2007;11:R84.

57. Makris K, Markou N, Evodia E, Dimiopoulou E, Drakopoulos I, Ntetsika K, et al. Urinary neutrophil gelatinase-associated lipocalin (NGAL) as an early marker of acute kidney injury in critically ill multiple trauma patients. Clin Chem Lab Med 2009;47:79-82.

58. Siew ED, Ware LB, Gebretsadik T, Shintani A, Moons KG, Wickersham $\mathrm{N}$, et al. Urine neutrophil gelatinase-associated lipocalin moderately predicts acute kidney injury in critically ill adults. J Am Soc Nephrol 2009;20:1823-32.

59. Wagener G, Minhaz M, Mattis FA, Kim M, Emond JC, Lee HT. Urinary neutrophil gelatinase-associated lipocalin as a marker of acute kidney injury after orthotopic liver transplantation. Nephrol Dial Transplant 2011;26:1717-23.

60. Abraham BP, Frazier EA, Morrow WR, Blaszak RT, Devarajan $\mathrm{P}$, Mitsnefes $\mathrm{M}$, et al. Cystatin $\mathrm{C}$ and neutrophil gelatinaseassociated lipocalin as markers of renal function in pediatric heart transplant recipients. Pediatr Transplant 2011;15:564-69.

61. Poniatowski B, Malyszko J, Bachorzewska-Gajewska H, Malyszk JS, Dobrzycki S. Serum neutrophil gelatinase-associated 
lipocalin as a marker of renal function in patients with chronic heart failure and coronary artery disease. Kidney Blood Press Res 2009;32:77-80.

62. Damman K, van Veldhuisen DJ, Navis G, Voors AA, Hillege HL. Urinary neutrophil gelatinase associated lipocalin (NGAL), a marker of tubular damage, is increased in patients with chronic heart failure. Eur J Heart Fail 2008;10:997-1000.

63. Bolignano D, Basile G, Parisi P, Coppolino G, Nicocia G, Buemi M. Increased plasma neutrophil gelatinase-associated lipocalin levels predict mortality in elderly patients with chronic heart failure. Rejuvenation Res 2009;12:7-14.

64. Damman K, Van Veldhuisen DJ, Navis G, Vaidya VS, Smilde TD, Westenbrink BD, et al. Tubular damage in chronic systolic heart failure is associated with reduced survival independent of glomerular filtration rate. Heart 2010;96:1297-302.

65. Damman K, Ng Kam Chuen MJ, MacFadyen RJ, Lip GY, Gaze $\mathrm{D}$, Collinson PO, et al. Volume status and diuretic therapy in systolic heart failure and the detection of early abnormalities in renal and tubular function. J Am Coll Cardiol 2011;57:2233-41.

66. Shrestha K, Borowski AG, Troughton RW, Thomas JD, Klein AL, Tang WH. Renal dysfunction is a stronger determinant of systemic neutrophil gelatinase-associated lipocalin levels than myocardial dysfunction in systolic heart failure. J Card Fail 2011;17:472-8.

67. Damman K, Masson S, Hillege HL, Maggioni AP, Voors AA, Opasich C, et al. Clinical outcome of renal tubular damage in chronic heart failure. Eur Heart J 2011;32:2705-12.

68. Maisel AS, Mueller C, Fitzgerald R, Brikhan R, Hiestand BC, Iqbal N, et al. Prognostic utility of plasma neutrophil gelatinaseassociated lipocalin in patients with acute heart failure: The NGAL evaluation along with B-type natriuretic peptide in acutely decompensated heart failure (GALLANT) trial. Eur J Heart Fail 2011;13:846-51.

69. Bagshaw SM, Bellomo R, Devarajan P, Johnson C, Carvellas CJ, Kutsiogiannis DJ, et al. Review article: acute kidney injury in critical illness. Can J Anaesth 2010;57:985-98.

70. Lattanzio MR, Kopyt NP. Acute kidney injury: new concepts in definition, diagnosis, pathophysiology, and treatment. J Am Osteopath Assoc 2009;109:13-19.

71. Supavekin S, Zhang W, Kucherlapati R, Kaskel FJ, Moore LC, Devarajan P. Differential gene expression following early renal ischemia-reperfusion. Kidney Int 2003;63:1714-24.

72. Devarajan P, Mishra J, Supavekin S, Patterson LT, Potter SS. Gene expression in early ischemic renal injury: clues towards pathogenesis, biomarker discovery, and novel therapeutics. Mol Genet Metab 2003;80:365-76.

73. Yuen PT, Jo S-K, Holly MK, Hu X, Star RA. Ischemic and nephrotoxic acute renal failure are distinguished by their broad transcriptomic responses. Physiol Genomics 2006;25: 375-86.

74. Mishra J, Ma Q, Prada A, Mitsnefes M, Zahedi K, Yang J, et al. Identification of neutrophil gelatinase-associated lipocalin as a novel urinary biomarker for ischemic injury. J Am Soc Nephrol 2003;4:2534-43.

75. Devarajan P. Neutrophil gelatinase-associated lipocalin: a troponin-like biomarker for human acute kidney injury. Nephrology 2010;15:419-28.

76. Grigoryev DN, Liu M, Hassoun HT, Cheadle C, Barnes KC, Rabb H. The local and systemic inflammatory transcriptome after acute kidney injury. J Am Soc Nephrol 2008;19:547-58.

77. Mishra J, Ma Q, Kelly C, Mitsnefes M, Mori K, Barasch J, et al. Kidney NGAL is a novel early marker of acute injury following transplantation. Pediatr Nephrol 2006;21:856-63.

78. Parikh CR, Jani A, Mishra J, Ma Q, Kelly C, Barasch J, et al. Urine NGAL and IL-18 are predictive biomarkers for delayed graft function following kidney transplantation. Am J Transplant 2006;6:1639-45.

79. Kusaka M, Kuroyanagi Y, Mori T, Nagaoka K, Sasaki H, Maruyama T, et al. Serum neutrophil gelatinase-associated lipocalin as a predictor of organ recovery from delayed graft function after kidney transplantation from donors after cardiac death. Cell Transplant 2008;17:129-34.

80. Lebkowska U, Malyszko J, Lebkowska A, Koc-Zorawska E, Lebkowski W, Malyszko JS, et al. Neutrophil gelatinaseassociated lipocalin and cystatin $\mathrm{C}$ could predict renal outcome in patients undergoing kidney allograft transplantation: a prospective study. Transplant Proc 2009;41:154-57.

81. Malyszko J, Malyszko JS, Mysliwiec M. Serum neutrophil gelatinase-associated lipocalin correlates with kidney function in renal allograft recipients. Clin Transplant 2009;23:681-86.

82. Malyszko J, Malyszko JS, Bachorzewska-Gajewska H, Poniatowski B, Dobrzycki S, Mysliwiec M. Neutrophil gelatinase-associated lipocalin is a new and sensitive marker of kidney function in chronic kidney disease patients and renal allograft recipients. Transplant Proc 2009;41:158-61.

83. Hall IE, Yarlagadda SG, Coca SG, Wang Z, Doshi M, Devarajan P, et al. IL-18 and urinary NGAL predict dialysis and graft recovery after kidney transplantation. J Am Soc Nephrol 2010;21:189-97.

84. Hollmen ME, Kyllonen LE, Inkinen KA, Lalla MT, Salmela KT. Urine neutrophil gelatinase-associated lipocalin is a marker of graft recovery after kidney transplantation. Kidney Int 2011;79:89-98.

85. Bataille A, Abbas S, Semoun O, Bourgeois E, Marie O, Bonnet $\mathrm{F}$, et al. Plasma neutrophil gelatinase-associated lipocalin in kidney transplantation and early renal function prediction. Transplantation 2011;92:1024-30.

86. Nauta FL, Bakker SL, van Oeveren W, Navis G, van der Heyde $\mathrm{JH}$, van Goor $\mathrm{H}$, et al. Albuminuria, proteinuria, and novel urine biomarkers as predictors of long-term allograft outcomes in kidney transplant recipients. Am J Kidney Dis 2011;5:733-43.

87. Clerico A, Giannoni A, Prontera T, Giovannini S. High-sensitivity troponin: a new tool for pathophysiological investigation and clinical practice. Adv Clin Chem 2009;49:1-30. 


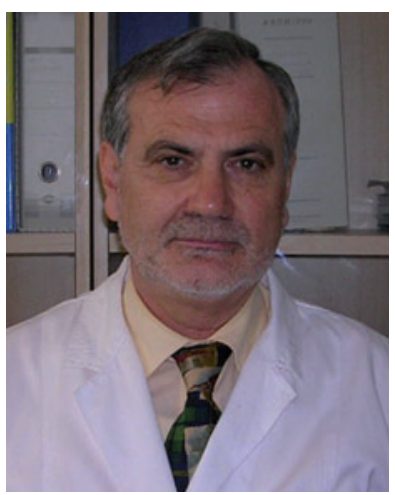

Aldo Clerico graduated in Medicine at the University of Pisa in 1973. He specialized in endocrinology in 1975, in nuclear medicine in 1978, and in sport medicine in 1987 at the University of Pisa. Since 2007, he has held the position of Director of the Department of Laboratory Medicine of the Fondazione Regione Toscana Gabriele Monasterio. He is also Associate Professor of Clinical Biochemistry at the Scuola Superiore Sant'Anna of Pisa since 2005. He has published more than 290 articles in international scientific publications. He has also participated as speaker or chairman in more than 150 national or international meetings.

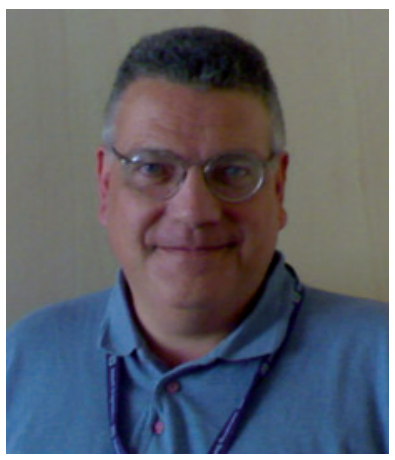

Claudio Galli, MD, PhD graduated in Medicine in 1980 and specialized in gastrointestinal diseases in 1984 (University of Roma "La Sapienza"). In 1988, he gained a $\mathrm{PhD}$ in infectious diseases with a research project on occult hepatitis $\mathrm{B}$ virus (HBV) infection in patients with HIV/AIDS. Main research interests: viral hepatitis A, B,

C (then non-A, non-B); HIV infection; E. granulosus. From 1998-2007, he was a Professor at contract the University of Roma "La Sapienza", specialty schools of Microbiology and Clinical Pathology. He currently holds the position of Scientific Affairs Manager at Abbott Diagnostics, Italy; principal fields of activity are: infectious diseases (viral hepatitis, retroviruses, ToRC); tumor markers; immunosuppressant drugs; markers for cardiovascular, renal and metabolic diseases. He is also a reviewer for Clinical Microbiology and Infection, Blood Transfusion, BMC Gastroenterology. He has also had 204 papers published in national and international journals and participated as a speaker in more than 100 congresses and CME courses.

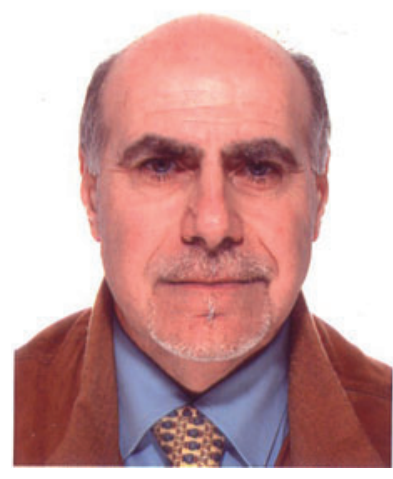

Antonio Fortunato graduated in biology from the University of Padua, Italy in 1980. From 1981 to 1983 he has been cooperator for a research project supported by the National Research Council (CNR) at the Pediatric Clinic of the University of Padua. Since 1984 he has been responsible for immunoassay section of the Clinical Pathology and Haematology Laboratory at St. Bortolo Hospital, Vicenza, Italy he is known to be "highly specialized" in this area. He holds the position of "contract professor" at University of Padua and Verona, Italy. Dr. Fortunato has co-authored 250 papers, and he has delivered more than 180 lectures at national meetings. He is a council member of Italian Scientific Societies, SIBioC and ELAS.

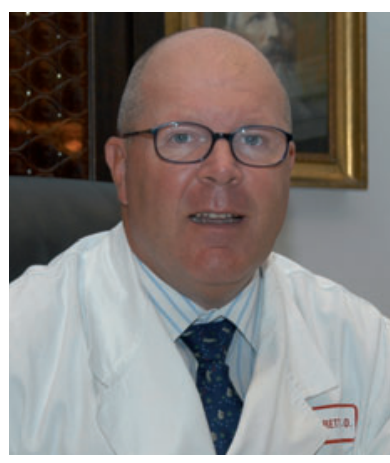

Claudio Ronco graduated in medicine from the University of Padua, Italy in 1976. In 1979 , he specialized in nephrology at the University of Padua, and in 1989, he specialized in pediatric nephrology at the University of Naples. In 1999 and 2000, he was Director of the Renal Laboratory of Research at the Renal Research Institute of New York and Professor of Medicine at the Albert Einstein College of Medicine and Beth Israel Medical Center of New York. Since 2002, he has been Director of the Department of Nephrology of St. Bortolo Hospital, Vicenza, Italy. Professor Ronco has co-authored 950 papers, 80 book chapters and 59 books, and he has delivered more than 450 lectures at international meetings and universities. He is a council member of several scientific societies. He is Editor Emeritus of the International Journal of Artificial Organs, and he is Editor-inChief of Blood Purification and Contributions to Nephrology. Professor Ronco has received numerous honors and awards, including, in 2004, a lifetime achievement award, honorary membership of the Spanish Society of Nephrology, and the National Kidney Foundation International Medal of Excellence. 